\$c This subfield will contain all but the first character (or all but the first if a longer escape sequence is used) of every escape sequence found in the record. If the same escape sequence occurs more than once, it will be given only once in this subfield. The subfield is repeatable. This subfield does not identify the default character sets.

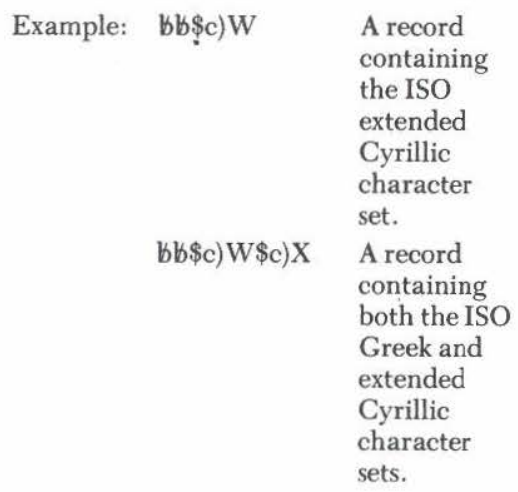

\subsection{Discussion-Other Details}

When a field has an indicator to specify the number of leading characters to be ignored in filing and the text of the field begins with an escape sequence, the length of the escape sequence will not be included in the character count.

When fields contain escape sequences to languages written from right to left, the field will still be given in its logical order. For example, the first letter of a Hebrew title would be the eighth character in a field (following the indicators, a delimiter, a subfield code, and a three-character escape sequence). The first letter would not appear just before the end of field character and proceed backwards to the beginning of the field.

A convention exists in descriptive cataloging fields that subfield content designation generally serves as a substitute for a space. An escape sequence can occur within a word, after a subfield code, or between two words not at a subfield boundary. For simplicity, the convention that an escape sequence does not replace a space should be adopted. One other convention is also advocated: when a space, subfield code, or punctuation mark (except open quote, pa- renthesis or bracket) is adjacent to an escape sequence, the escape sequence will come last.

Wayne Davison of RLIN raised the following issue. After the Library of Congress has prepared and distributed an entirely romanized cataloging record for a Russian book, a library with access to automated Cyrillic input and display capability will create a record for the same book with the title in the vernacular. (Since AACR2 says to give the title in the original script "wherever practicable," the library could be said to be obligated to do so.) In such an event the local record could have all the authoritative Library of Congress access points. To keep this record current when the Library of Congress record is revised and redistributed, it would be necessary to carry the LC control number in the local record. Most automated systems are hypersensitive to the presence of two records with the same control number. The two records can be easily distinguished: in the Library of Congress record, the modified record byte in field 008 will be set to "o" and it will not have any 066 , character sets present field.

\section{A Comparison of OCLC, RLG/RLIN, and WLN}

\section{University of Oregon Library}

The following comparison of three major bibliographic utilities was prepared by the University of Oregon Library's Cataloging Objectives Committee, Subcommittee on Bibliographic Utilities. Members af the subcommittee were Elaine Kemp, acting assistant university librarian for technical services; Rod Slade, coordinator of the library's computer search service; and Thomas Stave, head documents librarian.

The subcommittee attempted to produce a comparison that was concise and jargonfree for use with the university community in evaluating the bibliographic utilities under consideration. The University Faculty Library Committee was enlisted to review this document in draft form and held three meetings with the subcommittee for that purpose. The document was also shared with library faculty and staff in order to elicit suggestions for revision. 
A copy of the draft was sent to each utility with a request for suggestions for correction and/or clarification of the report. Each of the utilities responded promptly, and their recommendations were reviewed by the subcommittee and have been incorporated into the report as it appears here.

In reading this report two considerations should be kept in mind: (1) the information is current as of December 1980, and (2) the efforts at brevity and jargon-free comparison may have resulted in oversimplification in some areas.

This report is one aspect of the sixmonths-long decision-making process that led the University of Oregon Library to select OCLC, Inc. (now the Online Computer Library Center).

\section{INTRODUCTION}

An online bibliographic utility provides computer services to member libraries who, in turn, contribute computer-readable records to a common database. The database is a collection of catalog records input by the members and other sources such as the Library of Congress, the Government Printing Office, and the National Library of Medicine. Use of the database is online, meaning that each member library accesses the computer directly and carries out its work in an interactive, conversational manner through a computer terminal located in the library. Communications with the central computer are carried over a leased long-distance telephone line. The bibliographic utility produces two primary products-catalog cards and magnetic tapes of a library's catalog records-and offers many other services for processing and bibliographic control in libraries.

In addition to providing the products and services of a bibliographic utility through the Research Libraries Information Network (RLIN), the Research Libraries Group (RLG) has three other goals: (1) to provide a structure through which common research library problems can be addressed, (2) to provide scholars and others with increasingly sophisticated access to bibliographic and other forms of information, and (3) to promote, develop, and operate cooperative programs in collection development, preservation of library materials, and shared access to research materials.

The purpose of this report is to provide an overview of considerations in selecting an online bibliographic utility and a comparison of the three utilities being reviewed by the University of Oregon Library. Each consideration is accompanied by a brief definition or explanation, and a summary of each utility's capability in providing the necessary services or products. An attempt has been made to distinguish between currently available services and those that are planned for the future, but technological and organizational changes in the utilities have complicated this task and, in some cases, made it difficult for the subcommittee members to distinguish between operational and projected capabilities.

\section{BASIC CHARACTERISTICS HISTORY \\ OCLC}

OCLC, Inc., was founded in 1967 by the Ohio College Association as the Ohio College Library Center, to be the first online shared cataloging network. It has since expanded beyond the confines of the State of Ohio and is currently used by nearly 2,400 member libraries in the United States and abroad. In 1977 it adopted its present name.

\section{$R L G / R L I N$}

The Research Libraries Group, Inc., was established in 1974 by four major research libraries. In 1978 it acquired from Stanford University the BALLOTS bibliographic data system, which became the foundation for RLIN (Research Libraries Information Network), RLG's wholly-owned bibliographic utility. Besides being the basis for RLG's cooperative processing activities, RLIN supports its other three programs: Shared Resources, Cooperative Collection Development, and Preservation. RLG presently has 23 owner-members.

\section{WLN}

In 1975 the Washington Library Network began testing its online system using as its base a computerized bibliographic database that several Washington libraries had been building since 1972 . WLN is a project of the Washington State Library and pres- 
ently has over 60 members, primarily in the Northwest.

\section{Membership Configuration $O C L C$}

OCLC had 2,392 member libraries, in early 1981 , including about 1,300 college and university libraries, 330 public libraries, 250 federal libraries, 145 special libraries, 77 law libraries, 71 members of the Association of Research Libraries, 168 medical libraries, 37 state libraries, and at least 48 art and architecture libraries.

\section{$R L G / R L I N$}

In December 1980, there were 23 ownermembers (2l university libraries, The New York Public Library, and the American Antiquarian Society), two associate members, two affiliate members, and several museum and three law library special members. Libraries which formerly contracted for BALLOTS cataloging services from Stanford University are still being served by RLIN. These include 52 libraries using RLIN for online cataloging and 136 libraries using RLIN on a search-only basis.

\section{WLN}

WLN had 65 members, in early 1981, including 34 college and university libraries, 21 public libraries, two special libraries, three state libraries, five law libraries, and the Pacific Northwest Bibliographic Center.

\section{Governance}

Methods of governance are of concern to libraries considering membership inasmuch as they determine to a great extent the responsiveness of the utilities to the needs of their members and the ability of members to participate in setting the direction and priorities for the utility.

\section{$O C L C$}

A 15-member Board of Trustees holds the powers and performs the duties necessary for governance (including filling management vacancies and approving policy and budgets). A Users' Council, elected by the members, participates in the election of trustees and represents the interests of the membership in an advisory capacity. It also must ratify amendments to the OCLC Code of Regulations and Articles of Incorporation. Of the 69 delegates to the Council, 44 are from academic libraries. Various advisory groups exist representing the interests of special groups within the membership, including a Research Libraries Advisory Group. Twenty regional networks contract with OCLC to provide services to their members. OCLC libraries in Oregon participate through the OCLC Western Service Center, Claremont, $\mathrm{CA}$, and are served by OCLC's Portland office.

\section{$R L G / R L I N$}

RLG/RLIN operates through a Board of Governors consisting of one representative from each full member institution with the President as chief operating officer. Standing committees for Collection Management, Public Services, Preservation, and Library Technical Systems \& Bibliographic Control; and Program committees for East Asia, Art, Law, Theology, and Music are composed of appointees from member institutions and report to the President.

\section{$W L N$}

An 11-member Computer Services Council is elected directly by the online participant libraries. Legal responsibility for WLN resides with the Washington State Library Commission.

\section{Financial Stability}

An indicator of a utility's financial stability is its proven ability to generate sufficient revenues to cover expenses with the least recourse to outside funding sources.

Financial stability in a utility is a concern to a library considering membership not only from the standpoint of a utility's mere survival, but because of its implications for future system developments, possible dramatic fee increases should outside funding evaporate, and maintenance of high quality services and products.

\section{$O C L C$}

OCLC, Inc., is a not-for-profit corporation, with tax-exempt status having been granted under section 501 (c) (3) of the Internal Revenue Code. It is self-supporting, receiving no government or private subsidies, 
and issuing no stock. Its revenues alone support existing operations, expansion, and research and development activities. Revenues result from fees charged member libraries for products and services. OCLC's estimated assets for fiscal year 1980 were over $\$ 55$ million and its revenues approximately $\$ 24$ million. Its revenue base is its 2,400 member institutions.

\section{$R L G / R L I N$}

The Research Libraries Group, Inc., is a tax-exempt corporation owned by its 23 owner-member institutions. Revenues result from fees charged members for use of the RLIN database. RLG currently must supplement this income with foundation grants and loans from Stanford University, because of relatively high development costs and relatively low revenues. As of this year, nearly $\$ 5.25$ million has been received in grants and a $\$ 2.2$ million loan was obtained, to be repaid by August 1986 .

RLG has projected that in 1982-83 ongoing operating costs will be met by feegenerated income. RLG's Board of Governors recently approved a new income/ expense structure to take effect September 1, 1981: “operating expenses matched by rates for services; system development matched by grants and loans; program and administration matched by a program partnership fee." This new program partnership fee will be a flat annual rate for full members in the range of $\$ 20,000$ to $\$ 25,000$.

A decline in the number of units cataloged by member libraries (due in part to decreased acquisitions budgets), which is the basis for fees charged, forced the Board to institute this new fee. RLG is encouraging member libraries to seek these additional funds from institutional sources outside the libraries' own budgets.

The new financial structure appears to reflect a recognition of the need for outside resources to provide for research and development for at least the immediate future, and at the same time an effort to reconcile income and expense in the areas of operating expenses and program administration. Its revenue base is its membership of 23 institutions. In the past RLG has estimated that financial stability would be reached when membership reached 35 , but it is unclear how the new rate structure will affect that projection.

\section{WLN}

The Washington Library Network receives revenues in the form of fees for services and products. As a division of the Washington State Library, it also receives some funding from the State of Washington. WLN has been the recipient of some outside grants, but does not appear to rely heavily upon grant monies to meet ongoing expenses or system development costs. WLN would like to lessen its dependency upon the State of Washington, and has taken the first step by broadening the base of its advisory committee to include out-ofstate members. Its revenue base is its membership of approximately 60 libraries. The committee preparing this report does not have information as to the proportion of revenues generated by fees. However, a recent (July 1, 1980) 10\% increase in service rates was put into effect for these stated purposes, among others: "to recover the cost of operation of the computer service" and to "allow a modest margin to insure stability."

\section{Track Record in \\ Meeting Past System \\ Development Deadlines}

Past success or failure in meeting announced deadlines for system developments may be indicative of future performance in this regard. All three utilities are heavily engaged in research and development and, while we are primarily interested in the features that are presently available, it is also important to try to gauge what each system will look like several years from now. The amount of information available to the committee varied according to the utility, so these columns are not directly comparable, but merely suggestive.

\section{$O C L C$}

OCLC tries not to attach dates to its projections because of early failures to meet announced deadlines. However, its interlibrary loan system was implemented one year early and its searching improvements are claimed to be ahead of schedule. The planned acquisitions subsystem had been 
scheduled for completion in Summer 1980, and is currently being tested by a small number of member libraries.

The conversion of OCLC's database to accommodate the new cataloging rules and include new forms of names was completed on schedule in December 1980. The serials union listing capability was also completed on time. (See p. [224])

\section{$R L G / R L I N$}

A study dated August 1978 performed for the University of California listed planned BALLOTS system developments with projected completion dates. This list follows, with actual completion dates or revised projections added: *

Network File System (now called "reconfigured database" by RLIN)

Projected January 1979

Revised projection April 1981

Serials cataloging

Projected January 1979

Actual completion late 1979

Authority control system, phase 1

Projected January 1979

Revised projection Spring 1981

Authority Linking and Control, phase 2

Projected Fall 1979

Revised projection Spring 1981

Generalized acquisitions

Projected Fall 1979

Revised projection (in two phases) June 1981, October 1981

Serials Control

Projected 1980

Revised projection post-1982

Library Management Information System

Projected 1979

No projected date, no resources allocated

Book/COM Catalog Interface

Projected 1980

Revised projection 1981

\section{$W L N$}

WLN's present online system was one year late, and its acquisitions module was also late. The processing of retrospective conversion tapes which had been three months behind was current by early 1981 ,

*Since 1978 the RLG Board of Governors has determined the order of priorities for research and development. with the exception of two special projects.

Large-scale system adjustments to accommodate new cataloging rules were completed on schedule, as was implementation of roll-microfilm catalogs.

\section{Database Size and Components}

The size and makeup of the utility's database is of concern to libraries considering membership because those factors have the greatest bearing on the library's likelihood of obtaining a large portion of its cataloging information from the system.

OCLC

Size.

Over 7.1 million bibliographic records (February 1981)

Books: 4.9 million (October 1979)

Serials: 341,000 (October 1979)

Other: 340,000 (October 1979)

Name authority records: 500,000 (est. by 1981)

Formats Available.

Books

Serials

Films (AV)

Maps

Manuscripts

Music recordings

Music scores

Sources of Data.

Member-contributed records

Library of Congress-produced Machinereadable cataloging records (MARC) (1968 to date)

Government Printing Office-produced records (cataloged directly into OCLC by GPO)

CONSER records (Conversion of Serials-a project of 15 major libraries to produce machine-readable serials cataloging records). Data are entered directly into OCLC, then authenticated by the Library of Congress and the National Library of Canada.

National Library of Medicine-produced records

Additional sources include the following databases:

Canadian MARC serials

Minnesota Union List of Serials

Pittsburgh Regional Library Center Serials 


\section{$R L G / R L I N$}

Size.

Over 3 million bibliographic records (June 1980)

Books: 2.5 million (June 1980)

Serials: 460,000 (June 1980)

Authority records: 1.6 million (early 1981) Formats Available.

Books

Serials

Films (AV)

Maps

Music recordings

Music scores

Sources of Data.

Member-contributed records

MARC (excluding 1968-1972)

GPO records (to be added Spring 1981)

CONSER records

Cataloging records from Columbia and Yale Universities and University of Minnesota Biomedical Libraries, previously put into machine-readable form, have been added to RLIN. Records from the New York Public Library, Northwestern and Pennsylvania State Universities will be added in the near future.

Additional sources include the Avery Index to Architectural Periodicals.

$W L N$

Size.

2 million bibliographic records (January 1981)

Authority records: 2.3 million (January 1981)

Holdings records: 2.3 million (December 1980)

Formats Available.

Books

Serials

Films (AV)

Music recordings*

Music scores*

Sources of Data.

Member-contributed records

MARC (1968 to date)

GPO records

CONSER records (except those not yet authenticated by the Library of Congress)

Machine-readable records from the University of Illinois will be added to WLN's

*Awaiting implementation by the Library of Congress. database on a weekly basis by mid-1981. Records from certain libraries in the Southeastern Library Network (SOLINET) will be added in the future, as part of an arrangement whereby WLN made its computer software package available for use by Illinois and SOLINET.

\section{RESOURCE SHARING Interlibrary Loan (ILL)}

ILL is the process by which library materials are lent and borrowed by libraries in the U.S. and foreign countries. A bibliographic utility provides two tools to aid in this process: an online union catalog used to determine which library owns the needed material, and a message switching system used to communicate among libraries and to carry out the transaction. ILL at the University of Oregon Library is currently accomplished using a large number of printed union catalogs and is communicated by mail or Western Union teletype. A bibliographic utility will not completely replace ILL transactions carried out in this manner. The number of requests for materials from the library collection will probably increase due to the "visibility" gained in the online union catalog.

\section{$O C L C$}

The OCLC database provides the largest online union catalog through a holdings record listed with each catalog entry. The ILL message system transfers records from the database to the lending library in a request form, automatically sends the request to up to five libraries, generates records on the status of each request, and provides statistics on ILL transactions. OCLC ILL transactions are generally faster than traditional methods of interlibrary loan because of the ability to move data directly from the online union catalog to the request form without re-typing and the ability to have requests automatically forwarded if a library is unable to fill the request immediately. OCLC's ILL subsystem has been in operation for a year and participating libraries have reported general satisfaction with its performance.

\section{$R L G / R L I N$}

The RLIN database provides an online 
union catalog through a holdings record listed with each catalog entry. Materials not located in the RLIN database may be referred to the Bibliographic Center at Yale University for further manual searching through printed union catalogs. The RLG Message System may be used to create and send ILL requests to other RLG libraries, though this system is not specifically designed as a comprehensive ILL support system. The Shared Resources Program committee has recently formed a task force charged with the responsibility to create a functional specification for an automated interlibrary loan system, and to determine the priority for its implementation. RLG resource sharing policy requires members to give priority to ILL requests from other RLG members, to suspend fees to members, to provide on-site access to users from members' libraries' institutions, and to provide free photocopies of non-circulating materials.

\section{WLN}

The WLN database provides an online union catalog through a holdings record listed with each catalog entry. This online union catalog includes the local library call number and, for serials, the specific holdings of the library. The WLN Resource Directory is a microfiche listing of the bibliographic and holdings information in the database. WLN offers no message switching system for ILL, though this is their highest priority for future development. In cooperation with Pacific Northwest Bibliographic Center, WLN is planning experiments with a message switching system for interim use until the comprehensive ILL system is developed.

\section{Cooperative Acquisitions}

Cooperation in purchasing library materials is done in order to minimize the duplication of expensive purchases and to ensure that important works are easily available to users of the library, whether they are actually owned or not.

\section{$O C L C$}

Member libraries may search the database to determine the holdings of particular items by other member libraries, in order to avert undesirable duplicative purchases.

\section{$R L G / R L I N$}

Members actively coordinate purchases of certain categories of materials in designated fields in order to avoid extensive duplication and to ensure that at least one copy of every item of research value be acquired by a member institution.

In support of this effort is an automated "cooperative purchase file," containing limited bibliographic information and acquisition decisions of RLG members for all new serials on order and for all expensive items ( $\$ 500$ or more).

Member institutions agree to develop conspectuses reflecting their level of holdings and development in certain fields (subjects, language, and formats). These conspectuses are time-consuming to develop. A survey of holdings in Chinese, Japanese, and Korean languages has been finished by 12 members. Older members have completed Language and Literature, Fine Arts, Philosophy, and Religion. History is expected by March, 1981, to be followed by the hard sciences. Based upon these conspectuses, RLG members will build a system-wide collection development policy. New members are expected to begin work on their conspectuses as soon as possible, but not necessarily immediately after joining RLG.

\section{WLN}

Members may search the database to determine the holdings of particular items by other member libraries, in order to avert undesirable duplicative purchases. Libraries may also search the in-process file to determine if items are on order by one of the 23 libraries using WLN's Acquisitions Subsystem.

\section{Support for Collection Development Activities}

A bibliographic utility is potentially useful for collection development in that it provides a large file of bibliographic records that may be searched to assist in a) determining the existence of published materials in specified categories (on a particular subject, by a particular author, in a particular series, for example), and b) obtaining cor- 
rect bibliographic information about specific items to assist in ordering them. Important features in a utility in this regard are database size and variety of access points (subject, author, series titles, etc.).

\section{$O C L C$}

Useful access points by which the database may be searched include:

- Personal author

- Corporate author

- Title

- Series title

- Variant names (e.g. Clemens or Twain)

- Conference names

The database must be searched using a "search key" (a code based upon a sequence of initial letters in the words to be searched), not real words.

\section{RLG/RLIN}

Useful access points by which the database may be searched include:

- Personal author

- Corporate author

- Conference names

- Title

- Series title

- Subject heading or call number range (excluding items cataloged by the Library of Congress)

- Publisher, using a truncated ISBN (International Standard Book Number) [restricted to items cataloged by the Library of Congress]

A search of RLIN is likely to produce multiple records for particular items because an item held by more than one member will be displayed for as many libraries as have cataloged it through the system. It is projected that by April, 1981, RLIN's "reconfigured database" will have solved that problem by attaching holdings information to one unified record. It will also have merged the two bibliographic subfiles (Library of Congress and member cataloging) so that access by subject heading, call number range, and ISBN will be available for the entire database.

\section{WLN}

Useful access points by which the database may be searched include:
- Personal author

- Corporate author or corporate author keyword (keyword searching permits the user to search for items using either the full heading: American Society for Information Science; or words from the heading: "society" and "information." This capability is useful when the complete phrase is not known.)

- Title

- Corporate or conference author/title series (keyword)

- Series title or truncated series title

- Subject heading and/or subdivision or truncated subject heading

- Corporate and conference name subject headings (keyword)

\section{Preservation of Library Materials}

All bibliographic utilities, because of their function as a union catalog of their members' machine-readable cataloging information, have some usefulness for libraries making decisions about preservation priorities. A library may, for example, choose to give preservation treatment to item A rather than item B because item B is owned by several other libraries in the vicinity, whereas item A appears to be unique. It must be remembered, however, that many older items will not appear at all, because they were cataloged long before the utilities came into existence.

\section{OCLC}

Members may search holdings information in the database to determine the relative rarity of an item that is a candidate for preservation treatment.

\section{RLG/RLIN}

Members may search holdings information in the database to determine the relative rarity of an item that is a candidate for preservation treatment.

A computerized list of members' micropreservation activities is provided.

Experimental programs are conducted to test new preservation technologies and applications of existing processes.

Preservation microfilming is being done for members by staff at Yale and Princeton.

Funds are provided to members for preservation activities. 
These activities are part of RLG's Preservation Program, one of its four major programs.

\section{WLN}

Members may search holdings information in the database to determine the relative rarity of an item that is a candidate for preservation treatment.

\section{TECHNICAL PRQCESSING Acquisitions}

The steps by which the library purchases books and other materials include:

1. Pre-order searching to determine that a requested item is not already owned by the library or on order.

2. Selecting a dealer likely to be able to supply desired item.

3. Placing the order.

4. Receiving the item.

5. Clearing the order records.

6. Processing the invoice for payment.

7. Maintaining precise accounting of all book funds.

8. Inquiring about the status of items which are not received when expected.

9. Cancelling orders and adjusting accounting records when items are not available.

At the UO most acquisitions forms and files are created and maintained manually. In an automated acquisitions system the placing of the initial order generates an acquisition record for each item, which is updated as the item moves through the cycle outlined above. This eliminates the need for maintaining separate files according to the status of an order.

\section{OCLC}

Operational. OCLC has an online nameaddress directory which presently can be searched while using other OCLC subsystems. This file contains information about publishing, educational, library, and professional organizations and associations. This information will be automatically transferrable to forms being produced online.

Planned. OCLC's Acquisitions Subsystem, which is presently being tested by se- lected member libraries, is projected to be generally available in Spring 1981.

When operational the Acquisitions Subsystem will permit users to:

Place orders for all types of bibliographic materials (forms generated will be sent directly to supplier with copy to library)

Renew subscriptions

Request publications or price quotations

Create deposit account orders

Send prepaid orders

Cancel orders

Create and adjust fund records

Receive periodic fund reports

\section{RLG/RLIN}

Operational. RLIN does not have an operational Acquisitions Subsystem. Stanford University is continuing to use a system developed as part of BALLOTS.

Planned. The RLG Board of Governors has approved functional specifications for an Acquisitions Subsystem to be introduced in two phases. By June 1981, RLIN plans to have a centralized in-process file which will contain records of all new orders, gifts, subscriptions, etc. of members, and will be able to support non-accounting aspects of the acquisitions process. The capability to store and maintain an online book fund accounting system will be achieved in October 1981.

RLIN expects to be able to support all files, processing, and products necessary to establish, coordinate, and monitor materials acquisitions from the point of selection decision, request, order, or receipt through completion of technical processing activity.

\section{WLN}

Operational. WLN's Acquisitions Subsystem, which has been operational since May 1978, is comprised of four files:

1. In-process file which supports the majority of acquisitions activities.

2. Standing orders file which has records for subscriptions and other items which are renewed or reordered on a continuing or periodic basis.

3. Name and address file which contains names and addresses of book dealers and other vendors, main libraries, branch libraries, etc.

4. Account status file which provides ca- 
pability to maintain up-to-date accounting. Information keyed into the terminal during the day is entered against the accounts nightly and is reflected in the account totals available online the following day.

Records of completed transactions are transferred to a magnetic tape history file and can be used for generating statistical and other reports.

With each step of the order cycle, appropriate forms and reports are generated. Special system reports reflecting the status of the four files may be generated on request. Instructions entered at the time of the initial order provide for automatic generation of notification forms for individuals requesting the specific item being ordered or inquiry notices for materials not received after a specified period.

Planned. Further refinements of the procedures and capabilities of the system.

\section{Cataloging}

The creation of a cataloging record involves:

1. Describing an item

2. Assigning headings for names of persons or organizations and titles by which the user might be expected to seek the item in the catalog

3. Assigning a unique call number which will place the item with others of a similar nature, and

4. Assigning subject headings which reflect the content of the item.

Because most libraries collect many of the same materials, the concept of sharing the responsibility for cataloging was developed which makes materials available more quickly at reduced cost. With the establishment of national and international cataloging rules and standards, and the growth of large online computerized databases, it is becoming increasingly feasible to have each item cataloged only once with that cataloging information available for all libraries to use. The Library of Congress catalogs approximately 250,000 titles per year into machine-readable form. This cataloging is available through each of the bibliographic utilities and may be used for the creation of local catalogs. When the Library of Con- gress has not yet cataloged a specific item, a utility member library may prepare the cataloging according to specified standards and enter its cataloging into the database for use by other member libraries and for its own catalog.

Another aspect of the cataloging activity is the creation of a local database which can be used as the basis of not only the local library catalog, but also of a local circulation, acquisitions, and serials system, as well as for regional union catalogs. In order to provide total access to a library's collection in this machine-readable database, information concerning every item in the library must be entered into the system. This process is called retrospective conversion.

During the retrospective conversion process the library can choose to eliminate existing inconsistencies in the treatment of library materials including reclassifying books so that most materials are retained in one main classification system.

The University of Oregon Library has as a long-term goal completing total retrospective conversion of its collection so that all materials can be searched and located in an online catalog.

\section{$O C L C$}

Operational. OCLC's online Cataloging Subsystem has been operational since 1971 . Based on the experience of similar libraries, the University of Oregon Library might expect to find entries in OCLC's database for over 90 percent of the items searched.* These cataloging records can be modified online or accepted as is. The local library's symbol is added to indicate that it has used the cataloging record and then presorted, alphabetized catalog cards are ordered. The cards are printed overnight and shipped on a daily basis. Many OCLC libraries print their call number labels by means of a printer attached to their terminal.

Once a cataloging transaction has been completed, it is not possible to retrieve your local modifications online in the OCLC system. The record of your transaction is stored and sent to your library on magnetic tape on a periodic basis. These magnetic archive tapes can be used by a vendor or ${ }^{*}$ See footnote on page 225 . 
local computing center to generate a local microform or online catalog, run a circulation system, etc.

It is presently possible to catalog most types of materials in the OCLC system including books, serials, microforms, motion pictures, music, sound recordings, maps, and manuscripts.

Increased emphasis has been placed on quality control and adherence to specified standards in the creation of cataloging records, but there is no official editing of cataloging records by OCLC staff.

In 1979-80 nearly 45 percent of the activity on OCLC's Cataloging Subsystem was related to retrospective conversion. OCLC's large database, extended hours of service, and special pricing schedules for retrospective conversion and reclassification make it attractive for these activities. OCLC charges 60 cents per retrospective conversion record during hours of peak system activity (prime time) and five cents per retrospective conversion record during less busy hours (non-prime time).

Planned. OCLC continues to explore means of improving quality control. After moving their central facility to new quarters in early 1981, OCLC will reconsider the possibility of storing and displaying the number and location of local copies of a title.

\section{$R L G / R L I N$}

Operational. At this time the University of Oregon might expect to find cataloging available for 70 to 90 percent of its ongoing work in RLIN. $\dagger$ A search of RLIN's database retrieves multiple records because each library's records are stored separately. The library selects the desired record, modifies or accepts it, enters the library's symbol, and orders cards which are printed nightly and sent in presorted, alphabetized batches. No call number labels are produced, and it is not presently possible to print labels from the terminal.

Local library modifications are accessible online. Magnetic tapes or cataloging transactions may be purchased and used to create local online or microform catalogs.

Most materials may be cataloged with RLIN including books, serials, microforms, motion pictures, music, sound recordings, and maps.

Member libraries agree to catalog in conformity with RLIN standards, but there is no formal editing of records by RLIN staff on an ongoing basis. Sample quality checking is the responsibility of a newly-created position of Quality Assurance Specialist.

With only 23 owner-members, RLG must carefully consider the impact on the system of allowing individual members to undertake retrospective conversion projects. Each project must be approved by the Board of Governors, and members are encouraged to seek outside financial support rather than asking RLIN for reduced rates. RLIN has just received a 1.25 million dollar grant including $\$ 600,000$ to support retrospective conversion projects. RLIN does not charge for retrospective records which are completely recataloged and upgraded with the book in hand. The prices for other levels of retrospective conversion cataloging range from fifty-five cents to $\$ 1.85$ per record.

Planned. In April 1981, RLIN plans to reformat its database so that there will be

$\dagger A$ wide range of success rates for searching each system are cited in the literature, each dependent on the sample procedures used. The University of Oregon Library had 100 items searched against each database. This sample excluded books with printed Library of Congress card numbers, and included books, serials, microforms, music scores, recordings, documents, and non-book materials. Of this sample OCLC found 96, RLIN found 65, and WLN found 38 . The range of figures cited in this report allows for variation between studies cited in the literature, word-of-mouth reports from librarians using these systems, and the University of Oregon Library's own sample. An analysis of this sample is being prepared.

Recent comparisons of searching success are found in the following: Linking the Bibliographic Utilities: Benefits and Costs, submitted to the Council on Library Resources . . . by Donald A. Smalley [and others]. Columbus, Ohio, Battelle, 1980; Matthews, Joseph R., "The Four Online Bibliographic Utilities: A Comparison," Library Technology Reports 15:6 (November-December 1979), p. 665-838; Tracy, Juan I. and Remmerde, Barbara, "Availability of Machine-Readable Cataloging: Hit Rates for BALLOTS, BNA, OCLC, and WLN for the Eastern Washington University Library," Library Research 1:3 (Fall 1979), p. 227-81. 
only one copy of each cataloging record. Member libraries' symbols and local cataloging information will be displayed with the appropriate records.

\section{$W L N$}

Operational. Based on the experience of others, the University of Oregon Library might currently expect to find cataloging records available for 50 to 70 percent of its ongoing work in the WLN database. ${ }^{*} \mathrm{Li}$ braries search WLN's database, accept or modify the cataloging records, and order cards and labels which are printed nightly and shipped weekly. (Card sets are not presorted for filing.)

Local cataloging information is accessible online through the library's WLN terminal. Magnetic tapes of a library's cataloging transactions may be purchased to run a local online or microform catalog. WLN also provides microform catalogs on either microfilm or microfiche.

Books, serials, and audio-visual materials, but not music, sound recordings, and maps may be cataloged on WLN's system.

Libraries cataloging in WLN must conform to well-defined WLN standards. New cataloging records go through an edit cycle and are reviewed by central WLN staff before being added to the WLN database. Presently this review takes about two weeks. During this period, the cataloging record may not be retrieved online.

The WLN batch Retrospective Conversion Subsystem has been operational since August 1980. Using this system a library enters brief cataloging records which are collected by the system and searched later as a unit through the WLN database. Records for which a match is found are billed at six cents. Records not matched are billed at one cent and may be searched again at a later date. Over 30 WLN libraries are using this capability, which can be made available to non-members under special circumstances.

Planned. WLN is considering dispersing among selected member libraries responsibility for editing member-created cataloging records. WLN will make music cataloging available within the near future.

\footnotetext{
${ }^{*}$ See footnote on page 225 .
}

\section{Serials Check-in}

Serials are publications issued in successive parts bearing numerical or chronological designations which are intended to be continued indefinitely. They include periodicals; newspapers; annual reports and yearbooks; journals, memoirs, proceedings and transactions of societies; and numbered series. The average research library will have between 15,000 and 20,000 such titles. Precise data must be maintained to enter each issue as received, to discover missing issues, to request replacements for missing issues, to monitor accounting information, to renew or cancel subscriptions, and to maintain binding information.

Serials files contain such information as title, relationship to earlier publications, name and address of publisher, volumes the library owns, call number and location, date, volume, and number of each issue, date each issue was received, subscription dates, price, etc.

At the University of Oregon Library all of this information is maintained in manual files. Once the serials check-in operation is computerized, it is possible to generate a wide variety of serials finding lists, analyses of serials subscriptions by subject, location, department, etc., and to provide current serials information online.

\section{OCLC}

Operational. OCLC introduced its Serials Control Subsystem in 1976 and improvements to the system in 1979. Participants create online local data records with information necessary to monitor and control each issue of each serial received by the library. Institutions can check-in currently received issues online.

A recent ancillary to this system is the ability to create and maintain online a cooperative record of serials owned by any group of institutions (a union list of serials).

Planned. OCLC plans to continue upgrading the capabilities of its Serials Control Subsystem as needed.

\section{RLG/RLIN}

Operational. None.

Planned. Automated serials check-in is one of several items listed for consideration 
after current development activities are released, probably in late 1982 . No resources are presently committed to this project.

\section{WLN}

Operational. While WLN has no current serials check-in capabilities, it does support maintenance of serials subscriptions in the Acquisitions Subsystem, including automatic renewal and reorder reminders. WLN also produces union lists of serials.

Planned. WLN is investigating existing commercially-created check-in systems to see whether they can purchase an existing system to incorporate into WLN's services.

\section{Management \\ Information}

Precise up-to-date information concerning library operations can be very useful in planning improvements in library services and in attaining efficient utilization of available personnel, resources, and materials. Without the computer, the laborious record-keeping necessary to obtain useful management information almost negates the benefits of having the information.

\section{$O C L C$}

Operational. OCLC produces cataloging, interlibrary loan, and serials check-in system use and system performance statistics on a regular basis. Libraries can make local arrangements to create additional analyses of the information stored on subscription archival tapes of their local cataloging activity. OCLC offers semimonthly, monthly, or quarterly accession lists of new materials cataloged by each library. These lists may be in call number or subject sequence. OCLC has produced some special studies for institutions based on their cataloging records.

Planned. When the Acquisitions Subsystem is operational, libraries may choose to receive a cumulative, monthly Fund Activity Report and a periodic, cumulative Fund Commitment Register. These reports will provide institutions with current financial control data.

OCLC plans to continue to develop its ability to provide management information.

\section{$R L G / R L I N$}

Operational. System use statistics are provided in the form of the monthly invoice, which may be used to monitor cataloging and public service activity, and may be broken down into appropriate accounts by pre-planning. Lists in call number order of materials cataloged by a library into RLIN could be produced from local printers attached to the terminal.

Planned. The generation of management information is a future development project; no special management reports are prepared presently. Among the management reports included in the specifications for the Acquisitions Subsystem, projected for implementation by October 1981, are status reports on in-process files, materials awaiting receipt, materials received, and book fund balances.

\section{WLN}

Operational. WLN produces aggregate system activity reports monthly, but does not analyze the cataloging activity or subject holdings. WLN's Acquisitions Subsystem can be used to produce acquisitionsrelated management reports concerning account transactions, account history, standing orders, renewals and reorders, receipts, detailed encumbrances, etc. A microform accession list by title is available. A general-purpose text-editing facility may be used by management to maintain data not derived from WLN operations and to produce formatted reports of this data.

Planned. WLN is developing the capability to store and maintain detailed collection information for each library online, including copy numbers and location symbols for each copy of a title owned by a library. No specific management information plans have been outlined at this point.

\section{PUBLIC SERVICES \\ Reference Use of the Utility's Terminal}

A bibliographic utility has potential for use in library reference services in three major areas:

1. Verification of bibliographic information. The utility's database may be searched for cataloging information 
not in the UO Library catalog. A verification search is made to locate a complete catalog description of a specific, known item and is carried out most easily using one of the unique numbers assigned to a publication (Library of Congress Card Number, International Standard Book Number, etc.). If one of these is not known, a combination of author and title words, or a "search key"* based on author and title is used to retrieve the information. Verification places a greater reliance on the quality of bibliographic information in the utility's database than on search techniques used to locate the information.

2. Compilation of subject bibliographies. The utility's database is searched through words in the titles and subject headings in a bibliographic record in order to produce a list of materials on a given subject. This subject query can be modified using the logical relationships AND, $\mathrm{OR}$, and NOT to indicate, respectively, limitations, synonyms, or exclusions in the search. The ability to obtain a printed list of references is convenient, if not required.

3. Compilation of author bibliographies. The database is searched to find all material created by a particular individual or corporate body. The size of the utility's database is a major consideration, as is the source of the cataloging found in an author search. Again, a printed list is necessary.

\section{$O C L C$}

The OCLC database can be searched in a variety of ways to support reference ser-

\footnotetext{
*A search key is a code based on a certain number of characters drawn from a particular element in the bibliographic reference. For instance, to find a record for William Manchester's American Caesar, an author/title search key using the first four letters of the author's name and the first four letters in the title would be MANC,AMER. Various combinations of letters are used to search author names, titles, or author/title combinations. A search key may not necessarily be unique to a given item, and may retrieve other items beside the one desired.
}

vices, though there is no subject search capability in the system. The following access points may be used in a search:
1. LC Card Number
2. International Standard Book Num- ber (ISBN)
3. International Standard Serial Number (ISSN)

4. CODEN (an abbreviation developed by Chemical Abstracts Service for designating periodical titles)

5. Government Documents Number

6. OCLC Identification Number

7. Personal author (search key, not full words)

8. Corporate author (search key)

9. Performer (search key)

10. Title (search key)

11. Author/Title (search key)

12. Series title (search key)

13. Variant names (search key)

14. Conference names (search key)

Searches may be restricted by year or by type of material, such as books, manuscripts, maps, etc. The logical operators AND, OR, and NOT are not used in OCLC. The OCLC search system is primarily based on search keys and is best utilized to locate a known item. Local printing is available on any OCLC terminal so equipped. There is one standard print format offered.

\section{RLG/RLIN}

The following access points may be used in a search of the RLIN database, though not all are currently active in each subfile of the database:
1. LC Card Number
2. ISBN
3. ISSN
4. CODEN
5. Government Documents Number
6. RLIN Identification Number
7. Call number (complete or trun- cated)
8. Recording Label Number
9. Personal author
10. Corporate authors or conference names (keyword or phrase)
11. Title words
12. Subject headings (keyword or phrase)

13. Music Publisher 
Truncation (searching of partial entries) is available to aid in searching incomplete entries and the logical operators AND, OR, and NOT may be used to broaden or restrict a search. Local printers may be attached to the RLIN terminals. A variety of print formats is offered. Plans include unified search access points for all subfiles of the database as of April, 1981.

\section{WLN}

The following access points may be used to search the WLN database:
1. LC Card Number
2. ISBN
3. ISSN
4. WLN Identification Number
5. Personal author
6. Corporate authors or conference names
7. Title words
8. Series title (complete or truncated)
9. Corporate or conference author/title series (keyword)
10. Subject headings (complete or trun- cated)

For a variety of reasons, the WLN search system is the most powerful of the three utilities. Truncation is available and the logical operators AND, OR, and NOT may be applied to broaden or restrict a search. Records may be printed locally in a variety of formats on any WLN terminal so equipped. WLN will also provide printing at the central computer for reference bibliographies. WLN search software may be purchased for local database management applications (see the section on Online Public Catalogs.)

\section{Links to Other \\ Computerized Services}

There are presently over 150 reference databases available through commercial computerized reference service vendors. During the last ten to fifteen years, standard bibliographic indexing and abstracting publications such as Chemical $A b$ stracts, Historical Abstracts and Dissertation Abstracts International have used computerized methods to organize and print references to periodical articles, reports, dissertations, conference papers, etc. The vendor creates a computer searchable version of the reference database and makes it available to libraries for a fee based on their use of the computerized search system. Membership in a bibliographic utility can provide two benefits in the use of other computerized reference services:

1. Discounts on fees through membership in large group contract administered by the utility.

2 . Access to the reference vendor's computer through the utility's terminal and communication network.

\section{$O C L C$}

OCLC's Affiliated Online Services program provides access at discounted rates to the information services of Bibliographic Retrieval Service (BRS), Lockheed Information Systems (LIS), and the New York Times Information Bank. OCLC's communications network does not yet permit users to link to the hosts using an OCLC terminal, though this capability is anticipated in the near future.

\section{$R L G / R L I N$}

RLIN does not offer a formal program in this area, though the RLG 40 terminal is compatible with other information retrieval systems.

\section{WLN}

WLN does not offer a program in this area, but anticipates offering access to BRS, LIS, and New York Times Information Bank.

\section{Circulation}

None of the bibliographic utilities under consideration currently support circulation functions on their computers. However, each system can provide a machinereadable archive tape of our cataloging information to be used in developing a computerized circulation system. In order to keep track of circulation transactions, it is necessary to have complete retrospective conversion of the UO Library catalog. Another important consideration is the transferability of data between the utility's computer and the circulation computer.

\section{$O C L C$}

OCLC anticipates offering support for local circulation systems on their computer 
for member libraries and will demonstrate their system in mid-1981. OCLC data has been successfully transferred to many local circulation systems.

\section{$R L G / R L I N$}

RLIN does not anticipate offering local circulation services for member libraries. RLIN data has been successfully transferred to several local circulation systems.

\section{WLN}

WLN does not anticipate offering local circulation systems on their computer for member libraries. WLN data has been successfully transferred to local circulation systems and an agreement has been reached with DATAPHASE, a computerized circulation system vendor, to discount purchase of their system by WLN member libraries.

\section{Public Online Catalogs}

Again, none of the bibliographic utilities under consideration currently support public online catalogs of an individual library's collection. A public online catalog requires further programming in order to make it easy for the public to locate materials of interest without extensive training; the bibliographic utility's searching procedures are too esoteric to be used by the general public. As in circulation, issues of data transferability and full retrospective conversion of the UO Library's catalog are paramount.

\section{$O C L C$}

OCLC does not currently encourage public access to their database and does not support use of local online catalogs on their computer due to the tremendous demand for computer resources exerted by 2400 member libraries. OCLC and RLG/RLIN are participating in a study of user requirements for a public online catalog. OCLC data has been successfully transferred to several local online catalogs, including Eugene Public Library's circulation and online catalog system, ULISYS.

\section{RLG/RLIN}

RLIN anticipates being able to offer public access to their database. They are participating in a study with OCLC of user requirements for such a system, but no date has been announced for the development of this capability in RLIN. RLIN data has been successfully transferred to a local public online catalog at Northwestern University.

\section{$W L N$}

WLN does not believe that a local online patron accessed catalog should be provided through the WLN computer, even though they anticipate having such a capability within one year. Instead, they encourage libraries to develop local systems for public access to the online computerized catalog and to obtain data from the WLN cataloging system. The University of Illinois is adapting the WLN computer search and database management software to provide a local online catalog and computerassisted instruction in its use for the public.

\section{Checklist for Cassette Recorders Connected to CRTs}

Prepared by Lawrence A. WOODS: Purdue University Libraries, West Lafayette, Indiana, for the Technical Standards for Library Automation Committee, Information Science and Automation Section, Library and Information Technology Association.

\section{INTRODUCTION}

A data cassette recorder connected to a printer port is an effective, low-cost method of collecting data in machine-readable form from display terminals such as the OCLC 100/105.

It is important that a data recorder be used rather than an audio recorder although the cassette itself can be a goodquality audio tape. It is also important to note that the data recorded on the tape are not the same as the data originally transmitted to the display terminal, but are simply a line-by-line image of what appears on the screen. A typical installation will have a minimum of two devices: one attached to the display terminal to collect data, and one attached to a printer or an input device to another computer for playback of the data.

There are more than 150 various data re- 